\title{
A interpretação e a tradução intersemiótica construindo uma ponte para a função autor
}

\author{
Verônica Braga Birello \\ Mestre em Letras - Linguística. Professora UEM - \\ Universidade Estadual de Maringá, Maringá- PR, \\ Brasil. \\ vbirello@gmail.com
}

Resumo: Este trabalho busca analisar como 0 tradutor ocupa a função autor, ao traduzir entre mídias. Assim, trabalhou-se com o livro Howl's moving castle, de Diana W. Jones e com sua representação cinematográfica Hauru no ugoku shiro, do diretor Hayao Miyazaki. Buscou-se construir uma ponte que ligasse os conceitos da análise do discurso francesa de Michel Foucault (2000) com as teorias de tradução e da adaptação de Linda Hutcheon (2011). Os resultados deste trabalho sinalizam para um diretor que se configura como autor de uma nova obra, por meio da transposição da obra para uma outra materialidade.

Palavras-chave: Análise do discurso; Tradução intersemiótica; Função autor

\section{Roselene de Fátima Coito}

Doutora em Letras, com estudos de Pósdoutorado na Ecole des Hautes Études en Sciences Sociales. Professora UEM - Universidade Estadual de Maringá, Maringá- PR, Brasil. roselnfc@yahoo.com.br

Abstract: This aim of this paper to analyse how the translator may occupy the position of an author function when $\mathrm{s} / \mathrm{he}$ translates between different medias. Thus, we dealt with the book Howl's moving castle by Diana W. Jones and its filmic representative, the movie Hauru no ugoku shiro from Hayao Miyazaki. We attempted at the building of a bridge that could connect French discourse analysis through Michel Foucault (2000) with the concepts of translation and adaptation concepts by Linda Hutcheon (2011). The results of this research point towards the idea of the director as the author of a new work through the transposition of a given work into another media.

Key-words: Discourse analysis; Intersemiotics translation; Author function 



\section{Introdução}

Com a criação do cinema no final do século XIX, fica claro que ele tinha o potencial necessário para contar romances e outras histórias, de forma diferente da que um livro poderia contar, e isso aconteceu tantas vezes com o passar dos anos que, segundo Hutcheon (2011), quando se pensa em adaptação, muitas vezes, restringimos o conceito a uma mera "transposição" dos livros para a tela e esquecemos que adaptação significa, também, tradução.

Dessa forma, neste trabalho busca-se criar uma ponte entre os conceitos de autoria, interpretação e tradução intersemiótica. Evocam-se as teorias da análise do discurso francesa de cunho foucaultiano, para discutir o conceito de autoria e função autor. Em seguida, buscase contextualizar a interpretação, discutindo os seus limites para entender a tradução como um gesto de interpretação possível. Para complementar o trabalho por meio de uma análise possível, utilizar-se-á como corpus a tradução do livro Howl's moving castle, de Diana Wynne Jones, para o filme Hauru no ugoku shiro, do diretor japonês Hayao Miyazaki.

O romance escrito por Jones faz parte do gênero literário maravilhoso, uma vez que se passa em um reino distante onde bruxas, castelos voadores, feitiços são comuns. O livro conta a história de Sophie, uma jovem que se acha a mais azarada de todas, uma vez que é a irmã mais velha de três e, na terra de Ingary, nada poderia significar mais azar do que isso. A Sophie só resta herdar a loja de chapéus da família, após a morte de seu pai. Ela trabalha para a madrasta sem receber nada, e faz os chapéus mais lindos da cidade. Embora não saiba, ela tem poderes mágicos.

Ingary está aterrorizada pela aproximação do castelo do bruxo Howl, famoso por roubar o coração das moças mais belas. Sophie, que se considera feia, não se 
preocupa. Contudo, por conta de um encontro imprevisto com o bruxo, vira alvo da outra vilã que amedronta o reino, a Bruxa das Terras Desoladas. Essa mulher joga um feitiço em Sophie por considerá-la uma ameaça para a realização das suas intenções com Howl. Sophie se transforma em uma velha de 90 anos e não pode contar para ninguém sobre o feitiço. Sendo assim, ela sai de casa e vai em busca de desfazer o terrível feitiço.

Quando parte nessa aventura, Sophie entra no castelo do mago Howl. Ela começa a prestar serviços de faxineira e faz um acordo com Calcifer, o demônio do fogo do mago. Assim um deve quebrar o feitiço do outro. Sophie faz inúmeras trapalhadas, e Howl, um bruxo egocêntrico e inconseqüente, acaba sendo mudado por sua bondade genuína.

No livro, a autora detalha muitas aventuras e episódios fundamentais para o entendimento do enredo. No filme, por sua vez, o diretor explora um contexto de guerra que não se encontra explicitado da mesma forma no livro. Dada a caracterização extensiva do presente artigo, no gesto de análise desenvolvido por esse trabalho, buscase evidenciar, por meio da caracterização da personagem Sophie, como o diretor ocupa nesse momento a função autor proposta por Foucault (2000). Isso quer dizer que Miyazaki ocupa a posição autor de uma obra diferente daquela apresentada no livro de Jones (2001). É importante ter em mente que as obras foram produzidas com quase 20 anos de diferença, o que, na passagem do século XX para o XXI, significa grandes mudanças tecnológicas, considerando a evolução cinematográfica e as mudanças sociais que possibilitaram a emergência desse discurso, a partir do discurso presente no livro.

\section{Contextualizando a autoria: função autor, interpretação e tradução}




\subsection{Do autor empírico ao autor discursivo: um percurso histórico}

Para pensar a autoria de acordo com as teorias da análise do discurso é preciso considerar a interpretação que, por sua vez, inclui questões como a obra e o leitor. Neste momento, buscou-se tratar da autoria de forma primeiramente genealógica, promovendo a visualização das condições de produção da posição sujeito autor com base em Foucault (2000) e Chartier (2012). Esse procedimento se mostra necessário, uma vez que a obra analisada neste trabalho se configura como um livro impresso em 2001, Howl's moving castle, escrito por Diane Wynne Jones. As reflexões sobre a autoria serão expandidas, uma vez que o trabalho abrange ainda o filme baseado no livro de Jones, Hauru no ugoku shiro, produzido por um estúdio de animações japonês chamado Ghibli e dirigido por Hayao Miyazaki, em 2004. Procurou-se entender como a autoria se ressignifica por meio da tradução intersemiótica. Sendo assim, entender o conceito de autoria do qual parte o presente trabalho se mostra essencial.

Em 1969 Foucault apresenta uma conferência intitulada "O que é um autor?", em que esboça uma cronologia do conceito de autoria. Em 2012, o historiador francês Roger Chartier retoma a conferência do filósofo francês para expandir historicamente a cronologia do conceito, passando do conceito de autor empírico para o de autor discursivo. Segundo Chartier (2012), retomando Foucault, a necessidade da autoria surge na Idade Média, por conta da Inquisição. Essa seria a segunda cronologia considerada por Foucault (2000), a Inquisição exige a autoria para todas as publicações, visto que o anonimato era considerado crime. Nesse momento histórico, o autor empírico deve poder ser identificado, uma vez que a censura regula o que pode ser escrito e lido.

Ao tratar da outra cronologia proposta por Foucault (2000), que versa sobre o constante vigiar do 
autor empírico na época da Idade Média, por questões relacionadas à censura de muitas publicações, Chartier (2012) considera relevante o estudo sobre o copyright, a história de seu surgimento e suas implicações dada a época quase concomitante de seu surgimento. Dessa forma, é necessário entender a aquisição de direitos do autor e a manutenção do poderio dos livreiros britânicos. As grandes mudanças relacionadas ao copyright tiveram origem na Inglaterra do século XVIII, com a Rainha Ana que, instituindo um novo estatuto, quebra o duplo monopólio dos editores que não permitia que autores ou moradores de outras cidades, que não Londres, viessem a se tornar editores. A resolução de 1709 , por sua vez, rompeu o direito absoluto sobre a cópia adquirida com o autor e instituiu o limite do direito sobre a cópia, entre 14 e 28 anos.

O autor empírico requer, perante a lei, o direito de editar seus escritos e de fazê-los circular. O poder violado do autor em meio a essa luta de poderes que permeia a sociedade fez, e ainda faz, com que se impulsionasse a inversão dos poderes: autor $\mathrm{x}$ editor. Somente por meio de uma briga jurídica, a questão da propriedade literária se resolve perante a justiça inglesa, dando origem a um modelo de editoração para o mundo ocidental. Essa visão sobre a história que envolve o surgimento da autoria formal é necessária para se entender as condições que permitem a Foucault (2000) falar sobre a função autor, uma vez que ele também parte dessa cronologia, mas não unicamente da perspectiva histórica, e sim de uma perspectiva filosófico discursiva.

Neste trabalho, parte-se do conceito de sujeito do discurso de Foucault (2000), para posteriormente pensar sobre a autoria do filme Hauru no ugoku shiro. Dessa forma, a autoria discursiva, por sua vez, não pensa em autor como um sujeito empírico, homem ou mulher que escreve e publica um texto, conceito visto até agora por meio 
de Chartier (2012). Michel Foucault (2000) questiona esse autor, indivíduo que existe como ponto de partida, como origem do discurso. Segundo ele, o processo de autoria ocorre em duas fases: em um primeiro momento, acontece a triagem de enunciados e, no segundo, a seleção e exclusão destes, gesto que constitui a função autor. Para ele, a autoria é um processo complexo que busca dar conta da rarefação da proliferação de sentidos. Foucault, referindo-se ao autor, diz:

Ele manifesta a instauração de um certo conjunto de discursos e refere-se ao estatuto desses discursos no interior de uma sociedade e de uma cultura. O nome de autor não está situado no estado civil dos homens nem na ficção da obra, mas sim na ruptura que instaura um certo grupo de discursos e o seu modo de ser singular (FOUCAULT, 2000, p. 46).

Sendo assim, a autoria se caracteriza por ser uma atividade complexa, na qual acontece um afastamento entre o nome do autor e o indivíduo real em que a autoria passa a ser uma categoria do discurso. Pensando nessa função autor, é importante pensar também na questão da interpretação, pois é através de seu estudo que a pluralidade autoral se confirma, uma vez que existe uma possibilidade grande, não infinita, porém, de elaborar interpretações para um mesmo texto.

\subsection{A interpretação como chave para a autoria discursiva}

Tendo traçado esse breve panorama histórico a respeito da autoria e de sua relação com a circulação do livro, procura-se considerar o processo de interpretação. Existem algumas possibilidades de se entender tal processo, por exemplo, vertentes tradicionais buscam a intenção do autor que está presente no texto como chave para o 
processo interpretativo, interpretando-o com base na materialidade textual apenas. Por sua vez, a Estética da Recepção defende que a significação dependerá muito mais da interpretação do leitor do que da materialidade do texto, já que, sobre ela, não existe uma verdade única e imutável, e sim gestos de interpretação realizados por seus leitores. Contrariando tal vertente interpretativa totalmente focada no leitor, estuda-se aqui a proposta de Eco (1993), que defende a interpretação limitada, no sentido de que não existem infinitas interpretações para um texto. Dito de outro modo, mesmo que a busca pela intenção do autor seja infrutífera e infundada, interpretar em vários sentidos só se torna um gesto válido quando os limites do texto são respeitados. Retomando os escritos de Eco (1993), existiria ainda uma possibilidade a partir da qual seria possível resolver o paradoxo da interpretação, essa possibilidade é chamada por ele de intentio operis ou intenção do texto.

Assim, entende-se que o texto que ocupa a posição anterior na linha temporal, no caso do corpus deste trabalho, o texto escrito Howl's moving castle, já carregaria a sua "intencionalidade". Num segundo momento, o texto evoca sua transformação, para que o que existe além dele e por meio dele possa emergir, ou seja, ele passa por um processo de reescritura, e nesse caso por meio de sua tradução, ou seja, o filme Hauru no ugoku shiro. Diferentemente do que diz Benjamin (2008), o texto não está garantindo apenas sua sobrevida com a tradução. Neste trabalho, considera-se que o texto, ao ser reescrito, faz com que emirjam novos efeitos de sentido. Para Walter Benjamin (2008), um teórico tradicionalista estruturalista da tradução, a tradução nunca poderá ser comparada com a "obra original". Todavia, neste trabalho, constata-se a impossibilidade de falar em original, pois se considera que o indivíduo que ocupa a função autor o faz, em um dado momento, a partir de algo já existente no disperso de textos da formação discursiva. 
O próprio Eco (2000) retoma Foucault, com a problemática: "[...] um autor como 'modo de ser do discurso' campo de coerência conceitual e unidade estilística" (ECO, 2000, p. 3). E essa questão se encaixa neste momento devido ao corpus utilizado neste trabalho, um objeto literário. Foucault (2000), por sua vez, também fala dos espelhos, assim como Eco (1993), e, segundo ele, a linguagem estaria presa em infinitos espelhos que a refletem como se o interior no qual ela se apoia deixasse de existir gerando um novo paradoxo. Afinal é nesse interior que a obra se condensa para depois emergir. Não sobraria nada além do reflexo pálido de uma linguagem expandida até $\mathrm{o}$ infinito.

Segundo Eco (1993), é desde a Roma antiga que existe a busca pela "verdade secreta", aquela que é profunda, impossível de ser alcançada na superfície do texto. Certamente o significado não está presente apenas na materialidade do texto, seja ele de que gênero for. Contudo, mesmo que os interditos do discurso signifiquem, é preciso considerar a formação discursiva na qual o texto emerge e não tudo o que já foi dito em absoluto como se entrássemos na Bibliotèque de Babel. Mais que isso, existe uma única situação de produção que é diferente para cada enunciação. A situação de produção não é infinita, e justamente essa questão pode funcionar como limite e chave para a interpretação.

Ainda que algumas abordagens vigentes advenham do hermetismo, como aponta Eco (1993), é necessário levar em conta as considerações tecidas até este ponto, a fim de que a interpretação não se feche em uma verdade vazia, hermética, com infinitas possibilidades, muitas, porém, sem aplicação, que se resumem a meras especulações que têm como princípio: "Um texto é um universo aberto em que o intérprete pode descobrir infinitas interconexões" (ECO, 1993, p.45). E, nesse ponto, a palavra "infinitas" deveria ser 
substituída por "muitas", de acordo com a perspectiva defendida no presente texto. Não se pode esquecer que são os textos, formados por palavras ou imagens, que se prolongam até nós, em diferentes existências. Nas palavras de Foucault:

Poderia muito bem acontecer que em toda obra a linguagem se superpusesse a si mesma em uma verticalidade secreta em que o duplo fosse o mesmo exatamente de igual finura - fina linha negra que nenhum olhar pode descobrir salvo em momentos acidentais ou combinados de emaranhamento... (FOUCAULT, 2000, p. 51).

${ }^{1}$ o papel do leitor tradução livre.
E justamente neste momento que o autor se ausenta, atravessando um espaço virtual onde a linguagem se faz imagem para si mesma. Sendo assim, existem efeitos que estão presentes na página escrita, na imagem que se projeta na tela do cinema, na imagem de um quadro, e outros efeitos que existem apenas quando produzidos por meio do leitor-interpretador. É nessa ausência do autor que o leitor se depara apenas com a intentio operis, momento no qual o texto deve servir de guia. A interpretação então é capaz de produzir um leitor-modelo, e não um autormodelo. Além disso, esse é o lugar de the role of the reader ${ }^{1}$ citado por Eco (1993), segundo o qual:

Um texto é um dispositivo concebido para produzir seu leitor-modelo. Repito que esse leitor não é o que faz a "única" conjetura "certa". Um texto pode prever um leitor-modelo com o direito de fazer infinitas conjeturas. O leitor empírico é apenas um agente que faz conjeturas sobre o tipo de leitormodelo postulado pelo texto. Como a intenção do texto é basicamente a de produzir um leitor-modelo capaz de fazer conjeturas sobre ele, a iniciativa do leitor-modelo consiste em imaginar um autormodelo que não é empírico e que, no fim, coincide com a intenção do texto (ECO, 1993, p. 75). 
Por fim, aborda a discussão sobre autor versus leitor, volta-se novamente para o texto, nesse caso de caráter literário. Obviamente não cabe a este trabalho definir o que é literatura, visto que se chegaria a uma complexidade como a definição de arte, de belo, de valor etc., sem obter de fato nenhuma resposta para o nosso propósito. Por ora basta dizer, apropriando-se do discurso de Foucault: "Essa presença da palavra repetida na escrita dá sem dúvida ao que chamamos obra um estatuto ontológico desconhecido para essas culturas nas quais quando se escreve, é a coisa mesma que se designa, em seu próprio corpo, visível, obstinadamente inacessível ao tempo" (FOUCAULT, 2000, p. 49).

Essas palavras às quais Foucault se refere são autorepresentações que buscam ser interpretadas a todo custo e formam o misterioso acervo literário que emerge a cada interpretação, tradução.

Dito isso, entende-se que a função autor só é possível por meio de um gesto de apropriação inicial de um leitor em potencial que escreve, que seleciona enunciados, que os exclui na sua produção de sentidos. A partir daí, o leitor pode ser interpretador ou tradutor, tendo em vista que o resultado da leitura de uma obra está sempre além da intenção do autor, tido como a origem daquele discurso. Esse leitor, quando se transforma em tradutor, passa a ocupar a função de sujeito autor. Nessa posição, ele trabalha com a intenção do texto, fazendo com que sua interpretação possa se encontrar naquela página primeira e se levantar em uma nova direção. Dessa forma, a questão do tradutor como autor será abordada a seguir para que o assunto possa ser pensado de maneira mais específica.

\subsection{A autoria na tradução: pensando a transposição entre materialidades}

Continua-se com o diálogo estabelecido com Foucault, para pensar na situação do autor, nessa condição 
de produção em que temos a obra de partida versusa obra de chegada em outra materialidade. Nesse ponto do trabalho, já foram discutidos aspectos fundamentais da autoria e da interpretação, portanto, torna-se necessário enfocar a questão específica da tradução. Primeiramente tratar-se-á de criar uma ponte entre Foucault e a tradução, e depois trabalhar especificamente a tradução intersemiótica, na qual se localiza o corpus deste estudo.

Tendo isso em mente, inicia-se por retomar Haroldo de Campos quando diz:"[...] não se trata de apresentar as obras literárias no contexto do seu tempo, mas antes, de representar, no tempo em que surgiram, o tempo que as conhece-vale dizer, o nosso" (CAMPOS, 1991, p.22). A partir dessa reflexão, é possível pensar que a autoria no campo da tradução, e também nesse caso da tradução intersemiótica, pode ser considerada um acontecimento. Foucault (1995), ao refletir sobre o acontecimento, caracteriza-o como aquilo que tira o sujeito da ordem do discurso vigente. Retomando sempre as noções apresentadas por Foucault, o acontecimento é um efeito de:

\begin{abstract}
Naturalmente o acontecimento não é nem substância nem acidente, nem qualidade nem processo; o acontecimento não é da ordem dos corpos. E, no entanto, ele não é nada imaterial; é sempre no nível da materialidade que ele tem efeito, que ele é efeito, ele tem seu lugar e ele consiste na relação de coexistência, na dispersão, no recorte, no acúmulo, na seleção de elementos materiais; [...] o acontecimento deveria avançar na direção paradoxal, à primeira vista, de um materialismo do incorporal (FOUCAULT, 1995, p. 23).
\end{abstract}

A função autor, nesse sentido, poderia ser vista também como um acontecimento, pois o autor é quem recupera um discurso que está ligado à história e a uma memória, um discurso que só existe porque houve uma condição de existência, emergência e possibilidade. Ao 
tomar posse desse discurso, ele não tenta recuperar sua originalidade, pois, mesmo que quisesse, isso não seria possível, ele é um acontecimento tal que rompe com a ideia de homogeneidade do discurso.

Dessa maneira, é possível pensar sobre os princípios de descontinuidade, de especificidade e de exterioridade definidos por Foucault (1995). Pela descontinuidade, o autor afirma que não existe um "dizer" escondido e que seria trabalho do autor-tradutor, nesse caso, buscá-lo, revelá-lo e restituir o seu significado ou palavra. Pela especificidade, não existe a busca de discursos prontos, prévios, ele é uma prática que o autor-tradutor impõe, e assim encontra um princípio de regularidade, não que este princípio estaria ali esperando para ser revelado. E, enfim, a exterioridade, pela qual o discurso pode ter uma regularidade, que não se repete, é única para cada enunciado. Assim, pensando a tradução e a interpretação, pode-se citar:

[...] não ir do discurso em direção a seu núcleo interior e escondido, em direção ao núcleo de um pensamento ou de uma significação que se manifestariam nele; mas, a partir do próprio discurso, de seu aparecimento e de sua regularidade, ir em direção de suas condições externas de possibilidade, em direção ao que dá lugar à série aleatória desses acontecimentos e que lhes fixa os limites (FOUCAULT,1995, p. 21-22).

Ou seja, Miyazaki, diretor do filme, pode explorar vastamente os detalhes descritos por Jones (2001), assim como pode criar e interpretar os mesmos aspectos. Ele não vai em busca desse núcleo escondido, inexistente também para Foucault (1995). Miyazaki delimita o seu texto de acordo com o verdadeiro de sua época, o possível. Como um sujeito com sua memória coletiva específica, com sua própria historicidade, sua tradução é fruto de um gesto de interpretação do texto, assim como outras traduções e leituras, seja no mesmo meio ou entre meios, são sempre 
diferentes. Fato que permite retomar Campos (1991), quando escreve:

[...] O tradutor constrói paralelamente (paramorficamente) ao original o texto de sua "transcriação", depois de "desconstruir" esse original num primeiro momento metalinguístico. A tradução opera, portanto, graças a uma deslocação reconfiguradora, a projetada reconvergência das divergências, ao "extraditar" o "intracódigo" de uma para outra língua, como se na perseguição harmonizadora de um mesmo telos (CAMPOS, 1991, p.18).

Nesse momento, ao pensar a tradução com essa "reconfiguração" apontada por Campos, encontra-se o momento de abordar a tradução intersemiótica propriamente dita. Campos (1991) fala sobre um deslocamento que, por sua vez, reconfigura, pensando na transposição das materialidades. Tratando desse tipo de tradução que foi descrito pela primeira vez, segundo Plaza (2008), por Jakobson, temos a tradução intersemiótica, que consiste na interpretação e reconfiguração de um sistema de signos para outro.

Hutcheon (2011) confirma a ideia de que a tradução intersemiótica mais considerada é a de obras literárias para o meio cinematográfico. Embora a autora trabalhe sempre com o termo adaptação, para este trabalho, optou-se por tradução intersemiótica, uma vez que se entende que a autora faz uma aproximação entre os conceitos. De acordo com Hutcheon (2011, p. 69), "Os romances contêm muitas informações que podem ser de imediato traduzidas para a ação ou atuação no palco ou na tela, ou simplesmente de pronto descartadas". E um outro aspecto de relevância é a passagem não só da narração, como também da descrição presente no texto.

Dessa forma, é possível refletir sobre o fato de que, no caso da obra focalizada, Howl's moving castle, por ser um conto de fadas maravilhoso, muito de suas descrições, tanto 
de fatos como de personagens, puderam ser trabalhadas de forma cuidadosa e distinta porque a sua materialidade fílmica era uma animação, em vez de um live action, ou seja, filme interpretado por pessoas reais em cenários reais. De fato, toda mudança de materialidade requer esforço; não se pretende dizer que o diretor teve mais facilidade quando traduziu um conto de fadas para um filme de animação, entretanto, teóricos tradicionalistas poderiam dizer que a "perda" foi menor, afinal, um conto maravilhoso com seus elementos irreais, poderia ser melhor traduzido para uma materialidade que não se realizasse com elementos reais, comparando com um live action.

Após tecer tais considerações, busca-se exemplificar de forma prática a função autor na tradução intersemiótica e para isso a análise será focada na personagem Sophie e nas transformações sofridas pela personagem, no decorrer da história.

\section{Contextualizando um gesto de análise}

No movimento de análise proposto, serão analisados trechos selecionados com as descrições do livro fonte em comparação com a imagem apresentada no filme. No primeiro trecho selecionado, o "Quadro I", temos a protagonista da história, Sophie, com algumas de suas características físicas alteradas.

\begin{tabular}{|l|l|}
\hline Trechos do livro & Frames do filme \\
\hline O sério vestido cinza não \\
combinava com Sophie, ainda \\
mais quando os olhos dela \\
estavam vermelhos de tanto \\
costurar, e, uma vez que o \\
cabelo dela tinha uma cor \\
avermelhada como palha, \\
nem o verde nem o pink \\
combinavam. (JONES,2001, \\
p. 12$)^{2}$
\end{tabular}

Quadro I: Sophie antes do feitiço

2 "The staid gray dress did not suit Sophie, particularly when her eyes were red-rimmed with sewing, and since her hair was a reddish straw color, neither did caterpillar green nor pink" (JONES, 2001, p. $12)$. 
3 "It was a face of a gaunt old woman, withered and brownish, surrounded by wispy white hair. Her own eyes, yellow and watery [...]" (JONES,2001,p. 28).
Embora algumas mudanças se façam presentes, ao ler o texto de Jones (2001) como, por exemplo, a mudança na cor de seus cabelos, que, de vermelhos, passam para castanhos, talvez, para Miyazaki o cabelo vermelho não fosse capaz de retratar a simplicidade da personagem, visto que no Japão as cores predominantemente naturais para os cabelos são preto ou castanho escuro. Embora o cabelo vermelho, ou ginger head, fosse perfeitamente normal para o contexto britânico, no qual se inseria Jones (2001), o vermelho poderia representar uma tintura, o que fugiria da imagem passada pela personagem, ao menos para o público oriental. Dessa forma, pode-se dizer que o filme pode gerar efeitos de sentido diferentes, dependendo do público em questão, não contemplando alguns efeitos que poderiam ser produzidos para o público ocidental e mantendo outros para o público oriental.

\begin{tabular}{|l|l|}
\hline Trechos do livro & Frames do filme \\
\hline "Era o rosto de uma senhora \\
abatida, murcha e amarronzada, \\
rodeada pelo cabelo ralo e \\
branco. Seus olhos, amarelos \\
e lacrimosos [...]" (JONES, \\
2001, p. 28)
\end{tabular}

Quadro II: Sophie sob o feitiço.

Na segunda passagem selecionada, é possível ver Sophie enfeitiçada. Nesse momento, suas características são mais aproximadas ao que fora apresentado no texto escrito. Sophie é uma idosa que sente o peso da idade em sua aparência e no vigor físico. Não se percebe grande mudança psicológica, uma vez que ela se considerava uma velha antes mesmo de ser enfeitiçada. 


\begin{tabular}{|l|l|}
\hline Trechos do livro & Frames do filme \\
\hline $\begin{array}{l}\text { No livro a aparência de Sophie } \\
\text { volta ao que era antes do feitiço, } \\
\text { não existe modificação. }\end{array}$ \\
\hline \multicolumn{2}{|c|}{ Quadro III: Sophie depois do feitiço } \\
\hline
\end{tabular}

Com o Quadro III, porém, Miyazaki configura-se como autor. Sophie se livra do feitiço e, para dar forças para Calcifer mover o castelo, entrega-lhe uma parte de seus cabelos. Nesse quadro, além dos cabelos curtos, nota-se que Sophie continua com o cabelo brancoacinzentado, a cor não muda, em contraponto com o livro, pois a cor dos cabelos da personagem volta a ser avermelhada. Esse fato pode ser interpretado como uma parte do dano causado pela Bruxa, que nunca se desfez, ou que continuará como marca de toda a aventura e das mudanças operadas na vida da personagem como uma marca de seu amadurecimento forçado. Sophie sempre foi responsável, cresceu sem a mãe, que morreu quando ela ainda era pequena, e teve o azar de ser a mais velha de três irmãs, o que era considerado muito ruim em Ingary. Após a morte de seu pai, ela assume a loja de chapéus de sua família, trabalha para a madrasta que não lhe paga e nem lhe dá muita atenção. Ao ser enfeitiçada, Sophie se torna uma velha de noventa anos fisicamente também, pois, apesar de ser ainda muito jovem, Sophie se sentia como uma inválida.

O diretor, ao executar a transposição do livro de Jones para a materialidade fílmica, lê a obra e, a partir de sua leitura e interpretação, desenvolve seu filme. Para Foucault (2000), a autoria seria uma prática, e o indivíduo ocuparia então a posição de sujeito autor em algumas situações. O filósofo diz: 
[...] esta regularidade da escrita está sempre a ser experimentada nos seus limites, estando ao mesmo tempo sempre em vias de ser transgredida e invertida; a escrita desdobra-se como um jogo que vai infalivelmente para além das suas regras, desse modo as extravasando. Na escrita, não se trata da manifestação ou da exaltação do gesto de escrever, nem da fixação de um sujeito numa linguagem; é uma questão de abertura de um espaço onde o sujeito de escrita está sempre a desaparecer (FOUCAULT, 2000, p. 35).

Assim, ao configurar a personagem, que passa por transformações diferentes das apresentadas no livro, Miyazaki faz com que a autoria de Jones (2001) na materialidade fílmica desapareça e que sua autoria aflore, pois, naquele momento, ele ocupa a função autor conceituada por Foucault.

\section{Considerações finais}

Neste artigo, buscou-se explicar a autoria desde seu surgimento, que implica a obrigatoriedade de um autor empírico, até a autoria discursiva, proposta por Foucault (2000) como uma função que não é estática e que é ocupada por sujeitos diferentes em cada momento. Sendo assim, como complementação, buscou-se basear o estudo na interpretação, pois se vê que o texto delimita o que pode emergir como verdade, como efeito de sentido. Consideramos que o leitor não pode interpretar em toda e qualquer direção, é preciso respeitar a intenção da obra, proposta de Eco (2000). A autoria e a interpretação promovem uma conexão necessária com a tradução, nesse caso, intersemiótica, à medida que o tradutor-autor exerce a função autor, ao transpor uma obra já existente para diferentes mídias.

O gesto de análise proposto se configura como uma leitura possível da obra, não se restringindo nem esgotando as possibilidades de análise. Quando o público 
leitor ou espectador fica frente a apenas uma das obras, ele poderá interpretar de acordo com os limites do texto a qual tem acesso, uma vez que, como exposto anteriormente, o filme e o livro isolados podem gerar efeitos de sentido diferentes entre si. Isso se dá por conta da diferença entre as obras. Embora tudo já tenha sido dito em algum momento, o autor tenta delimitar alguns sentidos, ao compor sua obra, e com esse trabalho é possível observar que isso se dá tanto no livro quanto no filme. 


\section{Referências}

BENJAMIN, W. A tarefa do tradutor, de Walter Benjamin: quatro traduções para o português. Trad. Fernando Camacho, Karlheinz Barck, Susana Kampff Lages e João Barrento. BRANCO, L.C. (org.), Belo Horizonte: Fale/ UFMG, 2008.

CAMPOS, H. Tradução e reconfiguração do imaginário: o tradutor como transfigidor. In: COUTHARD, M; CALDASCOUTHARD,C.R (org.) Teoria e Prática. Florianópolis: Editora UFSC, 1991,p.17-31.

CHARTIER, R. O que é um autor? Revisão de uma genealogia. Tradução de Luzmara Curcino; Carlos Eduardo de Oliveira Bezerra. São Paulo: EdUFSCAR, 2012.

ECO, U. Interpretação e Superinterpretação. Trad. MF. São Paulo: Martins Fontes, 1993.

ECO, U. Os limites da interpretação. Tradução de Pérola de Carvalho. São Paulo: Perspectiva, 2000.

FOUCAULT, M. A ordem do discurso. Tradução de Adalberto de O. Souza. Maringá: Universidade Estadual de Maringá, 1995. [Série Apontamentos, n. 29].

FOUCAULT, M. O que é um autor?Tradução de António F. Cascais e Eduardo Cordeiro. 4. ed. Lisboa: Vega. 2000.

HUTCHEON, L. Uma teoria da adaptação. Tradução de André Cechinel. Florianopolis: Editora da UFSC, 2011.

JONES, D.W. Howl's moving castle. New York: Harper Collins Publishers, 2001.

MIYAZAKI, H. Hauru no ugoku shiro. São Paulo: PlayArte, 2004. 1 DVD (120 min.), son. color. 
PLAZA, J. Tradução intersemiótica. São Paulo: Perspectiva, 2008.

[Recebido em 14 de maio de 2013

e aceito para publicação em 16 de dezembro 2013] 